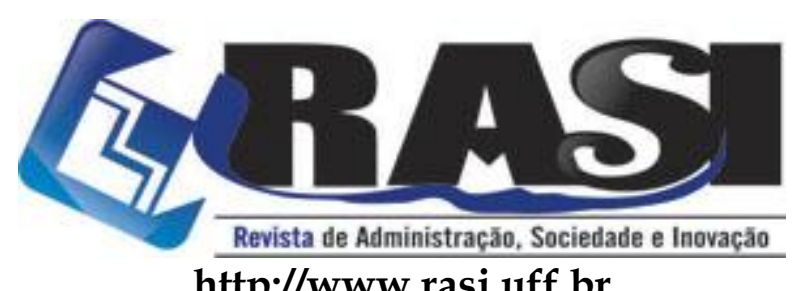

http://www.rasi.uff.br

RASI, Volta Redonda/RJ, v.4, n.1, pp.1-4, jan/jun. 2018.

\title{
Crescendo Sustentavelmente numa Linha Editorial Transparente
}

\author{
Márcio Moutinho Abdalla \\ Universidade Federal Fluminense - UFF \\ marcioabdalla@id.uff.br
}

\section{A Universidade \\ T. Federal \\ Fluminense}

R. Desembargador Ellis Hermydio Figueira, 783, Bloco A, sl. 304, Aterrado.

27213-145 - Volta Redonda, RJ - Brasil wWw.uff.br

Copyright @ 2018 RASI. Todos os direitos, até mesmo de tradução, são reservados. É permitido citar parte de artigos sem autorização prévia, desde que seja identificada a fonte. 


\section{Crescendo Sustentavelmente numa Linha Editorial Transparente}

Estimados leitores, compartilhamos o imenso orgulho de entregar a sexta edição da Revista de Administração, Sociedade e Inovação - RASI. A cada edição, procuramos revisitar nossos planos, olhando para nossas pegadas, como forma de melhor conduzirmos ações futuras (Mintzberg, Ahlstrand, \& Lampel, 2008). Nossa preocupação de ampliar a visibilidade da RASI, tanto no contexto brasileiro, quanto internacional, nasceu com a primeira edição, tendo ganhado vigor a partir do início de 2016, quando ampliamos consideravelmente a presença do periódico em indexadores (Abdalla, 2016). As decorrências previstas dessas ações vêm se concretizando de forma sistêmica - a RASI aumentou sensivelmente o número de trabalhos recebidos por mês, aumentando, por conseguinte, o crivo de qualidade e a demanda por mais avaliadores qualificados. Temos recrutado muitos avaliadores ao qual somos imensamente gratos. Graças a esse time de excelência, temos conseguido cumprir prazos honestos e respeitosos com autores, procurando fornecer, com celeridade, feedbacks úteis $\mathrm{e}$ construtivos. Acreditamos que num horizonte de médio prazo, teremos "fôlego" para incluir mais um número ao ano, o que pode ser considerado um grande feito, se partirmos do princípio que a RASI está completando apenas três anos.

Desde que o periódico nasceu, alcançamos posições animadoras. Até o momento, estamos presentes em 16 indexadores, bases de dados e diretórios de pesquisa, acessados ao redor do mundo. Tivemos um de nossos textos usados na prova de português da edição de setembro de 2016 do teste ANPAD. Conquistamos a classificação B3 pela CAPES em dois anos de trabalho. Fomos um dos primeiros periódicos nacionais a migrar para a moderna versão da plataforma OJS 3.0, que possibilita ampliar a versatilidade do processo editorial, além de aumentar a visibilidade dos trabalhos, em especial, por melhor dialogar com identificadores como DOI e ORCID. Em 2017, tivemos nossa primeira edição temática, conduzida com maestria pelo editor associado Prof. Ricardo César da Silva Guabiroba (Guabiroba, 2017). Ainda em 2017, fomos convidados a fazer parte de dois fast tracks, nos eventos XX SEMEAD e X CASI. Abrimos 2018 participando de quatro fast tracks - Primeira edição do Simpósio de Engenharia, Gestão e Inovação (SENGI), da UNESP; e dos seguintes eventos temáticos da ANPAD: VIII Encontro de Marketing da ANPAD (EMA); VI Encontro de Ensino e Pesquisa em Administração e Contabilidade (EnEPQ); e XXX Simpósio de Gestão da Inovação Tecnológica - certamente outros virão nesse ano! Estamos também nas redes sociais Facebook e Instagram, como forma de ampliar nosso diálogo com a sociedade.

Apesar de as demandas terem crescido significativamente, continuamos trabalhando em aprimoramentos que possibilitem mais transparência e qualidade das publicações e do processo editorial. A partir dessa edição, todas as referências de cada trabalho poderão ser acessadas na página de resumo do mesmo, permitindo rápido olhar sobre os artigos, antes mesmo de abrir o arquivo em formato PDF. A iniciativa também permitirá melhor análise do impacto de trabalhos citados nos artigos, especialmente em indexadores como o $\underline{\text { REDIB }}$, que reproduzirá em sua plataforma as referências de cada trabalho. 
Iniciamos a seção de artigos com o trabalho "Always On: tensions between the libertarian ideal and the surveillance and control potential in a hyperconnected society", de autoria dos professores Gustavo da Silva Motta (UFF) e Marcos Lima (Léonard de Vinci Pôle Universitaire, Research Center). No trabalho, os autores desenvolvem interessante contraponto entre a ideia de suposta liberdade(s) das sociedades hiperconectadas e os processos de vigilância e controle baseados na obra de Michel Foucault.

No segundo trabalho "Gestão do Conhecimento como Fator de Alavancagem de Inovação Aberta: o Caso Foco Virtual", os autores Eduardo Roque Mangini (UNINOVE), Fernando Henrique Brasil Rossini (UNINOVE), Marco Antonio Conejero (UFF) e André Torres Urdan (UNINOVE) desenvolvem um estudo de caso em que procuram compreender de que modo a gestão do conhecimento influi no desenvolvimento de produtos e serviços a partir do prisma da inovação aberta. Dentre os resultados apresentados pelos autores, destacamos a gestão do conhecimento como fomentadora da inovação aberta.

Lucas Stellin Miranda (USP) e Leonel Gois Lima Oliveira (UNICHRISTUS) assinam o terceiro trabalho, intitulado "A Análise da Implementação da Estratégia B2C em um Canal B2B: um estudo de caso da Coloplast". No artigo, os autores analisam a inserção da ótica do consumidor final no contexto de uma empresa dinamarquesa de dispositivos médicos. Em uma unidade habituada a operar sob a estratégia de B2B (Business to Business), analisa-se a implementação da lógica B2C (Business to Consumer), configurando-se numa abordagem híbrida de negócios.

Em “Inovação Responsável no Âmbito da Gestão e Negócios”, a autora Luciana Maines da Silva (UNISINOS) apresenta os resultados de uma investigação bibliométrica que objetivou analisar, no âmbito de gestão e negócios, a produção científica a respeito da aplicação do conceito de inovação responsável. Dentre os resultados apresentados pela autora, cabe destaque ao direcionamento dado aos trabalhos identificados, em sua maioria voltados à governança da inovação e sua respectiva relação com políticas públicas.

Renato Pereira Monteiro (IFRS - Campus Porto Alegre, bolsista CAPES) é autor do quinto trabalho dessa edição, intitulado "Análise Exploratória dos Fatores de Importância e Barreiras para a Implantação da Contabilidade de Custos no Setor Público Brasileiro". O autor traz importantes contribuições ao campo de conhecimento, ao revelar, num estudo qualitativo exploratório, fatores de importância, potenciais barreiras e benefícios na implementação do sistema de informação de custos no setor público brasileiro.

No sexto trabalho dessa edição, apresentamos o artigo "O Papel da Coopetição na Criação de Valor para Micro e Pequenas Empresas - MPEs no Âmbito da Cadeia de Suprimentos em Relações Fornecedor-Fornecedor", escrito por Silvio Bitencourt da Silva (UNISINOS) e Wilciney José Villan (FVA). No ensaio teórico, os autores discutem a geração de valor para Micro e Pequenas Empresas (MPEs) a partir dos processos de coopetição, nas relações fornecedor-fornecedor, no âmbito da cadeia de suprimentos. Os autores também analisam as decorrências desses processos no desempenho organizacional, tomando por base as teorizações de Visão Baseada em Recursos (VBR) e uma de suas variantes, a Visão Baseada em Conhecimento (VBC). 
Em nome da equipe editorial, agradecemos a todas as pessoas que contribuíram com a construção dessa edição e desejamos a todos uma excelente leitura!

Márcio M. Abdalla

Editor Chefe

\section{Referências}

Abdalla, M. M. (2016). Editorial: A Salutar busca pela Transparência em Pesquisas. Revista de Administração, Sociedade E Inovação, 2(1), 1-3.

Guabiroba, R. C. da S. (2017). Editorial: Primeira edição temática da RASI. Revista de Administração, Sociedade E Inovação, 3(2), 100.

https://doi.org/10.20401/rasi.3.2.196

Mintzberg, H., Ahlstrand, B., \& Lampel, J. (2008). Strategy Safari: The Complete Guide Through the Wilds of Strategic Management. Free Press (2nd Editio). Edinburgh: Prentice Hall. 